\title{
Memetic algorithm used in a flow shop scheduling problem
}

\section{Algoritmo memético utilizado en la programación de actividades de talleres de flujo continuo}

RAMOS-FRUTOS, Jorge Armando*†, CARRILLO-HERNÁNDEZ, Didia, BLANCO-MIRANDA, Alan David and GARCÍA-CERVANTES, Heraclio

Universidad Tecnológica de León

ID $1^{\text {st }}$ Author: Jorge Armando, Ramos-Frutos / ORC ID: 0000-0002-5743-9343, Researcher ID Thomson: X-5622-2019, CVU CONACYT ID: 903848

ID $1^{\text {st }}$ Coauthor: Didia, Carrillo-Hernández / ORC ID: 0000-0001'9989'5884, Researcher ID Thomson: ABF-4839-2020, CVU CONACYT ID: 936937

ID $2^{\text {nd }}$ Coauthor: Alan David, Blanco-Miranda / ORC ID: 0000-0002-8595-8634, Researcher ID Thomson: W-9701-2019, CVU CONACYT ID: 298274

ID $3^{\text {rd }}$ Coauthor: Heraclio, García-Cervantes / ORC ID: 0000-0002-4229-9229, Researcher ID Thomson: X-5622-2019, CVU CONACYT ID: 290829

DOI: $10.35429 / J M Q M .2020 .6 .4 .8 .14$

Received March 28, 2020; Accepted June 10, 2020

\begin{abstract}
Scheduling activities in flow shops involves generating a sequence in which the jobs must be processed. To generate the sequence, some criteria are taken into account, such as the completion time of all the jobs, delay time in delivery, idle time, cost of processing the jobs, work in process, among others. In this case, completion time of all jobs and idle time are taken as the objective function. To generate the sequence, a Memetic Algorithm (MA) is used that combines Simulated Annealing (SA) and Genetic Algorithms (GA) to solve the problem. A permutation type decoding was used for the vectors that make up the MA population. The SA was used for the generation of the initial population. Selection, recombination and mutation processes are generated in a similar way to GA. In this case there are 6 parameters to be set; temperature, $\mathrm{z}$ parameter, recombination probability, mutation probability, cycles and initial population. To set these parameters, the Response Surface Methodology is used for two objectives. Achieving improvements in the algorithm result of at least $2 \%$. These results help to minimize processing times which impacts with the economics of the enterprise. Using the MA in an interface that helps the user to make a decisión about the Schedule of the Jobs.
\end{abstract}

Memetic Algorithm, Parameters, Response Surface Methodology

\section{Resumen}

La programación de actividades en talleres de flujo continuo implica la generación de una secuencia en la que los trabajos se deben procesar. Para generar la secuencia se toman en cuenta algunos criterios como el tiempo de finalización de todos los trabajos, el tiempo de retraso en la entrega, el tiempo ocioso, entre otros. En este caso se toman como función objetivo el tiempo de finalización de todos los trabajos y el tiempo ocioso. Para generar la secuencia se utiliza un Algoritmo Memético (AM) que combina el Recocido Simulado (RS) y Algoritmos Genéticos (AG) para la solución del problema. Se utilizó una decodificación del tipo permutación para los vectores que conforman la población del AM. Se utilizó el RS para la generación de la población inicial. Los procesos de selección, recombinación y mutación se generan de forma similar al AG. En este caso existen 6 parámetros a ser fijados; temperatura, parámetro $z$, probabilidad de recombinación, probabilidad de mutación, ciclos y población inicial. Para fijar esos parámetros se utiliza la Metodología de Superficie de Respuesta para dos objetivos. Logrando mejoras en el resultado del algoritmo de al menos el 2\%. Estos resultados ayudan a minimizar tiempos de procesamiento lo cual impacta de forma económica. Utilizando el AM en una interfaz que ayude al usuario a tomar una decisión.

Algoritmo Memético, Parámetros, Metodología de Superficie de Respuesta

Citation: RAMOS-FRUTOS, Jorge Armando, CARRILLO-HERNÁNDEZ, Didia, BLANCO-MIRANDA, Alan David and GARCÍA-CERVANTES, Heraclio. Memetic algorithm used in a flow shop scheduling problem. Journal-Mathematical and Quantitative Methods. 2020. 4-6: 8-14

\footnotetext{
* Correspondence to Author (email: jramosf@utleon.edu.mx)

$\uparrow$ Researcher contributing first author
} 


\section{Introduction}

The Memetic Algorithm is a metaheuristic that contains a part of code corresponding to the Genetic Algorithm and another part corresponds to another metaheuristic. The Memetic Algorithm promises better results than those obtained when using each technique separately. Better results are obtained because they have exploration and exploitation qualities.

In scheduling operations, $\mathrm{n}$ jobs should be sequenced across $m$ workstations, minimizing the completion time for all jobs. Metaheuristics are techniques used to solve this job sequencing problem. It is intended to decide which metaheuristics is better than others. For this, comparisons between metaheuristics are made. Statistical evidence is sometimes generated to support decisions to choose the best technique. With the Memetic Algorithm there are improvements of up to $2 \%$ in various cases. $2 \%$ improvements over other metaheuristics.

This document presents the operations programming sections that describe the job sequencing problem and the types of configurations used in manufacturing companies. Mention is also made of the characteristics of the problem to be solved. The Genetic Algorithm, Simulated Annealing and Memetic Algorithm sections describe the process of each of the metaheuristics. The process adapts to the problem with permutation coding. The methodology describes the activities carried out to reach the results.

For the results, the comparison of four metaheuristics is shown: Memetic Algorithm, Genetic Algorithm, Simulated Annealing and Taboo Search. And a hypothesis test is shown for paired populations between the Memetic Algorithm and the Genetic Algorithm, reaching the conclusion that there is a significant difference between the makespans of the two techniques. And the Memetic Algorithm is taken as the winner.

Finally, we talk about the conclusions in which it is said that improvements of up to $2 \%$ were achieved in some cases. Even a little $2 \%$ is an economic saving for the operations of any plant.

\section{Operations Scheduling}

Operations scheduling is a decision-making process that is used in manufacturing companies. In general, it is about establishing the resources that will be used to carry out certain jobs in a certain interval of time. The activity scheduling is about contributing to the improvement or optimization of some index (completion time, delivery delays, percentage of use, inventory in process, etc.) [V].

Within the scheduling, the jobs must be sequenced taking into account some decision rules and the configuration of the production system. The configuration of a continuous flow shop is very common in manufacturing environments. In this configuration $\mathrm{n}$ jobs are processed by a series of $\mathrm{m}$ stations optimizing an objective function [XII]. There are a large number of variants, and they all have the following characteristics in common [IX]:

1. The number of workstations $m$ is at least 2.

2. All jobs are processed following the same production flow: station 1, station $2, \ldots$, station $\mathrm{m}$.

3. Each job $\mathrm{j}$ requires a processing time $\mathrm{p} \_\mathrm{jk}$ at station $\mathrm{k}$.

4. The machines are always available and never stop working.

5. Each machine can process at most one job at a time.

6. Preparation times for all jobs are zero.

7. No interruptions are allowed.

8. The changeover times are independent of the programs and are included in the processing times.

9. Changeover times and technology restrictions are deterministic and known in advance, as with delivery dates.

Some of the variants are shown below:

Job Shop Scheduling. It consists of a finite set of jobs, where each job is divided into operations or activities, these operations will be processed or executed on a certain number of resources or machines, each job has its own route of activities to follow. 
Task Scheduling. There is a set of tasks, each of them is associated with a certain duration of time, the objective is to program the tasks on machines, seeking the most appropriate order, assuming that for a task to be executed, its predecessors must be executed.

Flow Shop Scheduling Problem. It consists of a number of jobs that are processed on a number of machines, each job in the same order. The following variety of problems is encountered

Basic Flow Shop. It is considered a general case of the Job Shop differing from it because the jobs to be processed follow the same processing route through a series of machines organized in a linear manner.

Permutational Flow Shop. In this configuration, the initial sequence of the work carried out in the first stage is maintained for the rest of the stages of the line, therefore there are $n$ ! possible sequences as a solution to this problem.

Flow Shop without and with Buffer. A system without a buffer or with a null capacity buffer is one that at the end of a task on a certain machine, it cannot advance to the next machine in its processing path if there is another task being executed on that machine, which prevents the job from progress and therefore remains blocking the machine that has already finished its task and likewise blocking access to the jobs that follow the stalled job.

Hybrid Flow Shop. It is a special case of Flow Shop where in each stage there can be more than one machine and these are known as parallel machines, which are classified as:

- Identical: with equal processing times for all machines.

- Uniform: when the processing times have a parametric relationship between them.

- Not related: when processing times cannot be expressed through a parametric relationship.
- While in the basic Flow Shop, since there is only one resource per stage, it is only necessary to make the decision of the sequence of tasks, in the Hybrid Flow Shop two decisions must be made: the assignment of the jobs to the machines of each stage and the sequence of work on the different machines.

- $\quad$ Flexible Flow Shop. By including the concept of flexibility, a problem is encountered where jobs still follow a linear sequence through stages, but the system has the ability to allow jobs to skip one or more stages during processing, that is, it is about of jobs that do not need to be processed at all stages of the process. follows:

The objective function is stated as

"Objective Function": $\operatorname{Min} C_{\max }=C\left(J_{n, m}\right)$

Hold it:

$\sum_{j=1}^{n} z_{j, i}=1,1 \leq i \leq n$

$\sum_{i=1}^{n} z_{j, i}=1,1 \leq j \leq n$

$s_{1,1}=0$

$s_{1, i}+\sum_{j=1}^{n} t_{1, j} z_{j, i}=s_{1, i+1}, 1 \leq i \leq n-1$

$s_{r, 1}+\sum_{j=1}^{n} t_{r, j} z_{j, 1}=s_{r+1,1}, 1 \leq r \leq m-1$

$s_{r, i}+\sum_{j=1}^{n} t_{r, j} Z_{j, i}=s_{r+1, i}, 1 \leq r \leq m-1$,

$2 \leq i \leq n$

$s_{r, i}+\sum_{j=1}^{n} t_{r, j} z_{j, i}=s_{r, i+1}, 2 \leq r \leq m, 1 \leq$

$i \leq n-1$

$z_{j, i} \in\{0,1\}, 1 \leq j \leq n, 1 \leq i \leq n$

$s_{r, i} \geq 0,1 \leq r \leq m, 1 \leq i \leq n$

$t_{i, j} \geq 0$

\section{Genetic algorithms}

A genetic algorithm (GA) is an iterative search technique [XIII] that mimics the process of biological evolution of "survival of the fittest" $[X]$. The GAs do not seek to model biological evolution but to derive optimization strategies. 
The concept is based on the generation of populations of individuals through the reproduction of parents [VIII].

The process that a GA follows consists of generating an initial population randomly. After generating the initial population, some of the individuals are selected by some selection method. Some of them are stochastically taken from selected individuals to be recombined. Having the daughter individuals obtained from the recombination, some are selected in the same way as in the recombination process and the mutation operator is applied to them. Finally, $50 \%$ of the individuals are replaced in the initial population or in population i-1.

To solve the problem of sequencing tasks in continuous flow workshops, a permutation type coding must be used (figure 1) to solve the problem more easily.

\begin{tabular}{|l|lllllllll|}
\hline Chromosome A & 1 & 5 & 3 & 2 & 6 & 4 & 7 & 9 & 8 \\
\hline Chromosome B & 8 & 5 & 6 & 7 & 2 & 3 & 1 & 4 & 9 \\
\hline
\end{tabular}

Figure 1 Permutation Coding

Source: Sivanandam and Deepa

The selection, recombination and mutation operators are described below: The tournament selection operator consists of placing two individuals to compete and choosing from them the one with the best objective function. The single point recombination operator consists of dividing the individuals in two and that the part to the left of each individual remains, while the right part contains the natural numbers that remain and that are in the order of the other parent. And finally, the mutation operator consists of exchanging alleles of two positions. Figure 2 shows the AG pseudocode.

\section{Simulated Annealing}

The simulated annealing starts with a solution $\mathrm{X} \_0$ and from there it looks for random neighboring solutions. If this solution $X \_n$ is better than the previous one, it becomes the solution $\mathrm{X}_{-} 0$, in case such solution is not optimal, it saves the non-optimal responses as long as they are within the acceptance value of deterioration. This acceptance percentage decreases as the algorithm progresses. Accepting non-optimal solutions allows the search space to be slightly wider than the space where the last local optimum found is located.
Figure 3 shows the pseudocode of the Simulated Annealing algorithm.

\section{Genetic Algorithm Start \\ Define:}

\author{
Codification \\ Initial Population \\ Aptitud test \\ For $\boldsymbol{i}=1:$ cycles \\ Population (only if $i \geq 2$ ) \\ Aptitud test (only if $i \geq 2$ ) \\ Selection \\ Crossover \\ Mutation \\ the individuals obtained)

\section{End} \\ Makespan of $n$ jobs with $m$ machines \\ End of the Genetic Algorithm \\ Figure 2 Genetic Algorithm Pseudocode \\ Source: Self Made
}

Initial population quantity, jobs quantity, objective function, crossover probability, mutation probability, cycles.

Replacement (new population with the $50 \%$ of

\section{Memetic Algorithm}

The proposed Memetic Algorithm (AM) consists of generating the initial population using the SR and from that initial population continue with the selection, recombination, mutation and replacement operations used in the GA. The SR is used in the choice of the initial population for its exploitation capacity (capacity to find an optimum in a valley or a crest of the neighborhood of possibilities). And the $A G$ is used in the other operations for its exploration capacity (search capacity in the vicinity of possibilities). The AM pseudo-code is shown in Figure 4.

Four algorithms are used using ten cases: Taboo List, Simulated Annealing, Genetic Algorithms, and Memetic Algorithms. The cases are programmed in the different algorithms. Each case contains a certain number of workstations, certain jobs, and times for each job. Table 1 shows the characteristics of each case, in terms of number of jobs and stations. 
Simulated Annealing Start

Define:

Initial temperature, jobs quantity, objective function, quantity of machines, neighborhood, $\mathrm{z}$ parameter, cycles.

\section{Codification}

Initial Population

For $i=1$ : cycles

Random select of neighborhood elements

Generate a random number $(R)$

Obtain the probability like $P=e^{-Z}$

If (objective function) $)_{i-1} \leq$ (objective function $)_{i}$

$$
\text { schedule }=s_{k}
$$$$
T=0.5 * T_{i-1}
$$

If-else ((objective function $)_{i-1}>$

(objective function) $)_{i} \& R<P$

$$
\text { schedule }=s_{k}
$$$$
T=0.5 * T_{i-1}
$$

If-else $\quad(\text { (objective function })_{i-1}>$

(objective function) $)_{i} \& R>P$

$$
\text { schedule }=s_{k}
$$

End

$$
T=T_{i-1}
$$

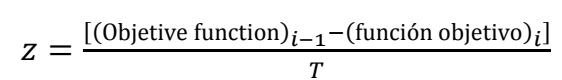

makespan $_{i}=(\text { objetctive function })_{i}$

End

Makespan of $n$ jobs with $m$ machines

End of the Genetic Algorithm

Figure 3 Simulated Annealing Pseudocode Source: Self Made

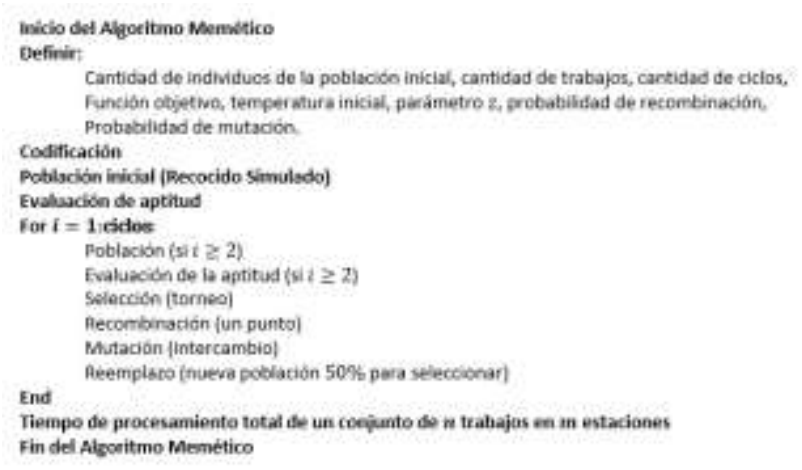

Figure 4 Pseudocode of the Memetic Algorithm Source: Self Made

\begin{tabular}{|c|r|r|r|}
\hline Case & \multicolumn{2}{|c|}{ Jobs } & \multicolumn{1}{c|}{ Seasons } \\
\hline CA01 & 20 & & 5 \\
\hline CA02 & 20 & & 5 \\
\hline CA03 & 20 & & 5 \\
\hline CA04 & 20 & & 5 \\
\hline CA05 & 20 & 5 \\
\hline CA06 & 20 & & 5 \\
\hline CA07 & 30 & & 10 \\
\hline CA08 & 40 & & 20 \\
\hline
\end{tabular}

Table 1 Cases to analyze

Source: Self Made
In the end, the two best results are chosen to compare them in several cases using a hypothesis test for two paired populations.

\section{Results}

Ten cases are analyzed with the aforementioned algorithms. The results are shown in Table 2.

\begin{tabular}{|l|l|l|l|l|l|}
\hline \multirow{2}{*}{ Case } & \multicolumn{4}{|c|}{ Makespan (Unit of time) } & \multirow{2}{*}{ Best } \\
\cline { 2 - 5 } & AM & AG & RS & BT & \\
\hline CA01 & 1141.8 & 1165.4 & 1180.0 & 1387.6 & AM \\
\hline CA02 & 1230.2 & 1230.4 & 1334.5 & 1578.5 & AM \\
\hline CA03 & 1269.5 & 1308.8 & 1370.7 & 1472.8 & AM \\
\hline CA04 & 1078.2 & 1079.8 & 1100.1 & 1274.4 & AM \\
\hline CA05 & 1312.4 & 1319.6 & 1385.2 & 1618.5 & AM \\
\hline CA06 & 1317.0 & 1319.4 & 1404.9 & 1566.2 & AM \\
\hline CA07 & 1297.8 & 1301.7 & 1418.5 & 1590.1 & AM \\
\hline CA08 & 2471.0 & 2490.8 & 2595.3 & 2935.8 & AM \\
\hline
\end{tabular}

Table 2 Comparison of results between the four algorithms

Source: Self Made

In all cases, it is conclusively shown that $\mathrm{AM}$ is better than the algorithms: AG, RS and BT. But you can see a little difference between AM and GA. Therefore, it is decided to carry out a test of the hypothesis of the difference of means for paired populations. The following null and alternative hypotheses are proposed:

$$
\begin{aligned}
& H_{0}: \mu_{D}=0 \\
& H_{1}: \mu_{D} \neq 0
\end{aligned}
$$

A significance of $5 \%$ is proposed and the value of t_ 0 indicated by the test statistic is estimated. For this case, a value $t=-4.76$ was generated. It is known that it is a two-tailed test and there is a "value-" $p=0.00103$ that concludes that there is a significant difference between the two algorithms. Having better results the AM. Graph 1 shows the box-andwhisker plot. The diagram shows that the AM has results loaded on the left; times less than AG. And the objective function for this case is minimize. Therefore, it is concluded that AM is the best algorithm of the four metaheuristics reviewed. 


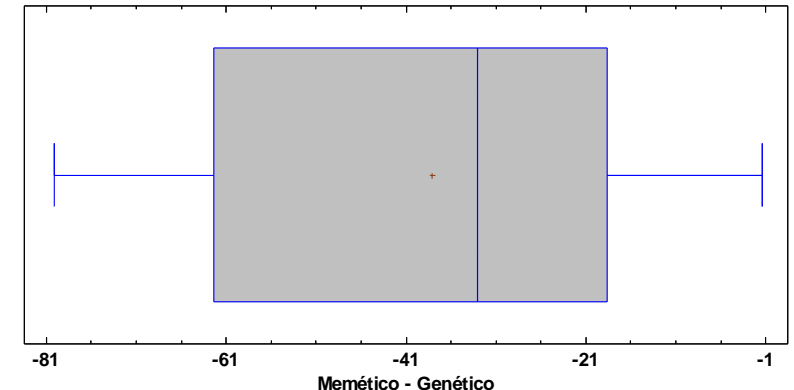

Graphic 1 Mean difference box and mustache; paired populations

Source: Self Made

To finish with the results, Graphic 2 is shown with the evolution of the results of each algorithm at the passage of each cycle in a problem of 40 jobs and 20 stations.

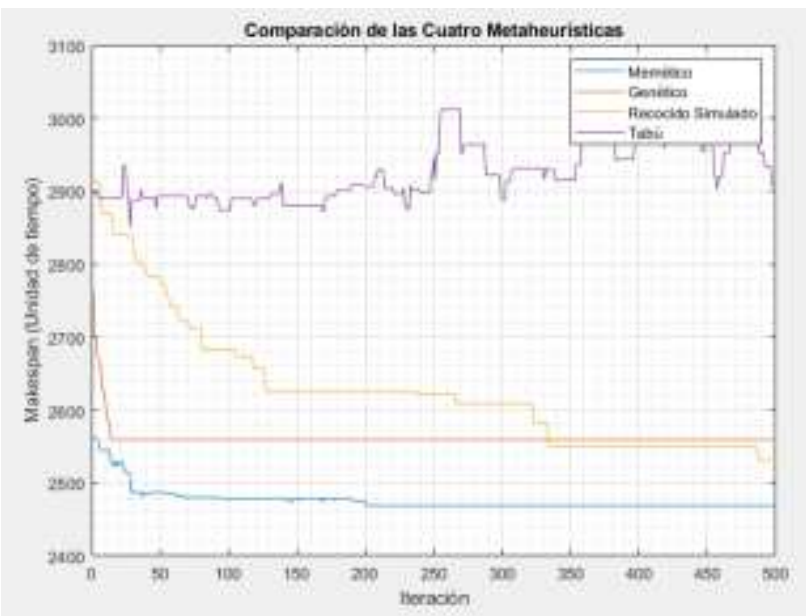

Graphic 2 Evolution of the makespan in each iteration by metaheuristics

Source: Self Made

It can be seen that the MA starts from a lower point by placing the RS in the generation of the initial population. This benefits exploitation and with the AG scan feature, better results are achieved than using each metaheuristic separately.

\section{Thanks}

Thanks to the Technological University of León for the support given to those interested in generating this knowledge.

\section{Conclusions}

It is concluded that when generating a hybrid with RS and AG, better results are obtained than using each one separately (improvements of up to $2 \%$ with respect to $A G)$.
It is intended to use AM in other contexts to check if there are differences with the other metaheuristics. It is intended that in a future work an interface for factories with a continuous flow workshop configuration that contains the $\mathrm{AM}$ is programmed for the generation of the processing sequence in the work plan.

\section{References}

[I]Gooding, W., Pekny, J., \& McCroskey, P. (1994). Enumerative approaches to parallel flowshop scheduling via problem transformation. Computers and Chemical Engineering, 909-927.

[II] Jacobs, F., \& Chase, R. (2014). Administración de operaciones. Producción y cadena de suministro. México: McGraw Hill.

[III] Jolai, F., Asefi, H., Rabiee, M., \& Ramezani, P. (2013). Bi-objective simulated annealing approaches for no-wait two-stage flexible flow shop scheduling problem. Scientia Iranica, 861-872.

[IV] Jolai, F., Asefi, H., Rabiee, M., \& Ramezani, P. (2013). Bi-objective simulated annealing approaches for no-wait two-stage flexible flow shop scheduling problem. Scientia Iranica, 861-872.

[V] Krajewski, L., Ritzman, L., \& Malhotra, M. (2008). Administración de operaciones; Procesos y cadenas de valor. México: Pearson Educación.

[VI] Kramer, O. (2017). Genetic algorithm essentials. Oldemburg: Springer.

[VII] Melab, N., Chakroun, M., Mezmaz, M., \& Tuyttens, D. (2012). A GPU-accelerated Branch-and-Bound Algorithm for the FlowShop Scheduling Problem. International Conference on Cluster Computing (págs. 10-17). Beijing : IEEE.

[VIII] Mirjalili, S. (2019). Evolutionary algorithms and neural networks. Theory and applications. Brishbane: Springer.

[IX] Öztop, H., Fatih, M., Türsel, D., \& Pan, Q.K. (2019). Metaheuristic algorithms for the hybrid flow shop scheduling problem. Computers and Operations Research, 177-196. 
[X] Ponce, P. (2010). Inteligencia Artificial con aplicaciones a la ingenieria. México: Alfaomega.

[XI] Ramos, J. (2001). Optimización de operaciones en la línea de producción para incrementar la productividad y disminuir el desperdicio. Monterrey: Universidad de Nuevo León.

[XII] Ruiz, R., \& Vázquez, J. (2009). The hybrid flow shop scheduling problem. European Journal of Operational Research, 1-18.

[XIII] Sivanandam, S., \& Deepa, S. (2008). Introduction to Genetic Algorithms. Berlin: Springer.

[XIV] Temiz, I., \& Erol, S. (2004). Fuzzy branch-and-bound algorithm for flow shop scheduling. Journal of Intelligent Manufacturing, 449-454. 